\title{
Automatic retrieval in directed forgetting
}

\author{
JENNIFER VONK and KEITH D. HORTON \\ Wilfrid Laurier University, Waterloo, Ontario, Canada
}

\begin{abstract}
In two experiments, we investigated the role of automatic retrieval in directed forgetting, using a stem completion test. In each experiment, we compared the performance of an implicit group, a process dissociation procedure (PDP) group, and a group given a speeded response task. The response times of the speeded response group on the stem completion task replicated earlier data in suggesting that this group adopted a purely automatic retrieval strategy. Experiment 1 revealed a directed-forgetting effect on automatic retrieval with the item method, but Experiment 2 revealed no directed-forgetting effect on automatic retrieval with the list method, consistent with the lack of implicit effects with the list method throughout the literature. Both experiments showed lower automatic estimates for the PDP group than for the implicit and speeded response groups, which did not differ. The data are consistent with either a selective rehearsal or an inhibition account of directed forgetting with the list method. The comparison of methods for assessing automatic retrieval is consistent with earlier evidence suggesting that subjects may adopt a generate/recognize strategy when given direct retrieval instructions.
\end{abstract}

In the directed-forgetting paradigm (see Golding \& MacLeod, 1998, for an extensive review), subjects study a series of stimuli one at a time. With the item method, each stimulus is immediately followed by a cue to either remember or forget that item for a subsequent memory test, whereas with the list method, subjects are given an instruction halfway through the list to forget the preceding items and to remember the next set of items. With both methods, the subjects later complete a memory test under instructions to retrieve all the items, regardless of whether they were cued to be remembered or forgotten.

A key empirical dissociation in the literature is that free recall of remember $(\mathrm{R})$ items is better than that of forget (F) items with both the item and the list methods; however, this directed-forgetting effect is evident on recognition tests only with the item method (Basden, Basden, \& Gargano, 1993; E. L. Bjork, R. A. Bjork, \& Anderson, 1998; but see Golding, Long, \& MacLeod, 1994). This pattern of data has contributed to the general consensus that different processes operate in the two paradigms (see, e.g., Basden \& Basden, 1998; E. L. Bjork et al., 1998; MacLeod, 1999). With the item method, differential processing of $\mathrm{R}$ and $\mathrm{F}$ items is generally acknowledged as

This research was supported by a Natural Sciences and Engineering Research Council Postgraduate Scholarship to J.V. and a Natural Sciences and Engineering Research Council Discovery Grant to K.D.H. We thank Barbara Basden, Glen Bodner, and John Vokey for their thoughtful reviews of this article. J.V. is now at the University of Southern Mississippi Gold Coast. Correspondence should be addressed to K. D. Horton, Department of Psychology, Wilfrid Laurier University, Waterloo, ON, N2L 3C5 Canada (e-mail: khorton@wlu.ca).

Note-This article was accepted by the previous editorial team, when Colin M. MacLeod was Editor. the source of performance differences: Subjects withhold processing of a word until they are cued to remember it. Thus, $\mathrm{R}$ words receive more extensive processing than do F words at study and are, accordingly, better remembered on both recall and recognition tests. Variables that minimize processing differences tend to reduce the directedforgetting effect (e.g., deep processing, Wetzel, 1975; relations among items, Horton \& Petruk, 1980; subjectperformed tasks, Earles \& Kersten, 2002).

By contrast, the common interpretation of findings from the list method is that the $\mathrm{F}$ cue results in retrieval inhibition of the F items (Basden \& Basden, 1998; E. L. Bjork et al., 1998; but see MacLeod, Dodd, Sheard, Wilson, \& Bibi, 2003). Retrieval inhibition can be caused by subjects' establishing a set or context for the items from the first half of the list and then changing to a new context as items from the second half are processed (Basden \& Basden, 1998; Basden, Basden, \& Morales, 2003; Sahakyan \& Delaney, 2003). ${ }^{1}$ This retrieval inhibition builds as subsequent $\mathrm{R}$ items are learned (E. L. Bjork et al., 1998; Conway, Harries, Noyes, Racsma'ny, \& Frankish, 2000). The lack of directed forgetting on a recognition test with the list method indicates that processing of $F$ items on the test releases retrieval inhibition (E. L. Bjork et al., 1998; R. A. Bjork, 1989).

According to some authors, conscious retrieval of the stored representation (Basden \& Basden, 1998) or conscious contact with the stored representation at retrieval (E. L. Bjork \& R. A. Bjork, 1996; E. L. Bjork et al., 1998) is required to observe directed-forgetting effects with the list method. Thus, "mere exposure" (E. L. Bjork et al., 1998 , p. 119) to $\mathrm{F}$ items does not reverse retrieval inhibition imposed during the study trial. Accordingly, directedforgetting effects would not be expected when subjects employ strictly automatic retrieval at test. The present re- 
search was designed to investigate the role of automatic retrieval in directed forgetting. We included an assessment of automatic retrieval with the item method of directed forgetting because retrieval inhibition has also been implicated there (Geiselman \& Bagheri, 1985; MacLeod, 1989; Zacks, Radvansky, \& Hasher, 1996). In addition, because there has been no clear resolution as to the most appropriate measure of automatic retrieval, we also compared methods for measuring automatic retrieval. We will begin with a brief summary of two of these methods: the process dissociation procedure (PDP) and the speeded response procedure.

\section{Process Dissociation Procedure}

In the PDP, the test instructions specify use of a direct retrieval strategy (Jacoby, 1998): The subject uses the test cue to simultaneously invoke automatic and conscious retrieval of previously studied information (Jacoby, 1998; Reingold \& Toth, 1996). An alternative retrieval strategy that a subject might adopt is generate/recognize: The subject uses the test cue to generate response alternatives from semantic memory and then invokes a recognition process to evaluate whether the retrieved information was part of the learning episode.

In addition to this key distinction between retrieval processes, the PDP incorporates two critical assumptions. The controversial independence assumption specifies that automatic and conscious retrieval are independent processes (Jacoby, 1998). The awareness assumption further specifies that awareness of the episodic history of a retrieved item is available to subjects when the item has been retrieved via conscious retrieval (Horton, Wilson, \& Evans, 2001; Reingold \& Toth, 1996), but not when it has been accessed via automatic retrieval alone.

These assumptions are operationalized in inclusion and exclusion tests. In an inclusion test, the subject is instructed to use the test cue to retrieve a studied item but, failing that, to use the first item that comes to mind. This task is designed to foster both conscious and automatic retrieval: Conscious retrieval is invoked by the instruction to use the test cue to retrieve a studied item, and automatic retrieval is invoked by encoding of the test cue. If conscious retrieval returns the studied item, the subject responds with that item. Otherwise, the automatic retrieval process will yield the first item to come to mind. In an exclusion test, the subject is again instructed to use the test cue to retrieve a studied item, but if he or she is successful, he or she responds with a different item. If the conscious retrieval process does not return a studied item, the subject responds with the first word that comes to mind (but see Snodgrass, 2002).

These assumptions allow for quantification of the conscious and automatic components of retrieval. Performance on an inclusion test is defined as

$$
I=C+A(1-C),
$$

where $I$ is the proportion of studied items given on the inclusion test and $C$ and $A$ refer to the respective contri- butions of conscious and automatic processes to performance. Performance on an exclusion test is defined as

$$
E=A(1-C),
$$

where $E$ is the proportion of studied items given on the exclusion test. The contributions of conscious and automatic processes can then be derived as

$$
C=I-E
$$

and

$$
A=\frac{E}{(1-C)} .
$$

Findings from the PDP have demonstrated that several variables affect the conscious, but not the automatic, component of performance (see, e.g., Jacoby, Toth, \& Yonelinas, 1993; Toth, Reingold, \& Jacoby, 1994). Using the PDP, Russo and Andrade (1995) found that directed forgetting is one such manipulation, although it is not certain that their test instructions satisfied the criteria for direct retrieval. Specifically, on the inclusion test, "subjects were asked to complete each fragment with a studied word," whereas on the exclusion test, "subjects were requested not to complete fragments with words previously studied" (p. 409, emphasis in the original). Instructions to use the test cue to recall the studied item are seen as essential to adopting a direct retrieval strategy (Jacoby, 1998; but see Bodner, Masson, \& Caldwell, 2000; Horton \& Vaughan, 1999). If subjects opted for a generate/recognize strategy, the process dissociation formulation would not apply, because the conscious and the automatic contributions to performance would not be independent. Consequently, their concerns regarding the observed inverse relation between conscious and automatic estimates may be unfounded.

\section{Speeded Response Procedure}

We have described an alternative procedure for isolating automatic retrieval processes (Horton et al., 2001; Horton, Wilson, Vonk, Kirby, \& Nielsen, 2005; Wilson \& Horton, 2002). The basis for this approach was the assumption that automatic retrieval is generally much faster than conscious retrieval (Richardson-Klavehn, Gardiner, \& Java, 1996; Toth, 1996), at least in a typical episodic memory experiment. The subjects in our speeded response group studied a list of words under various encoding conditions and then were given practice stem completion tests prior to a critical stem completion test. The purpose of the practice tests was to encourage the subjects to respond as quickly as possible to the stems (see also Vaterrodt-Plünnecke, Krüger, \& Bredenkamp, 2002), with no opportunity to use conscious retrieval, because stems on the practice test did not correspond to studied items. Subsequently, on the critical stem completion test, half of the stems could be completed with studied items. The time to respond on the critical stem completion tests did not vary from those on the practice tests, thereby supporting our hypothesis that the subjects were responding on the critical test by using strictly automatic retrieval.

This conclusion was further supported with data from two other conditions. In the explicit condition, the subjects 
received explicit instructions on the critical test. Response times (RTs) in this condition increased reliably (see also Richardson-Klavehn \& Gardiner, 1998; RichardsonKlavehn et al., 1996; Vaterrodt-Plünnecke et al., 2002), confirming that conscious retrieval takes longer than automatic retrieval. In the baseline condition, the subjects responded to stems of nonstudied items on both the practice and the critical tests. These subjects had no basis for switching to conscious retrieval on the critical test and thus presumably continued responding on the basis of automatic retrieval. Importantly, RTs on the critical test for the baseline group did not differ from those for the speeded response group, for which stems could be completed with studied items on the critical test. In all, these data provide strong support for the assumption that subjects in the speeded response group continued with an automatic retrieval strategy on the critical test. Because we have consistently found this pattern over several studies, we elected not to replicate the baseline and explicit groups in the present studies.

We have also demonstrated that variables yielding no effect on automatic estimates when the PDP is used (e.g., Jacoby et al., 1993; Toth et al., 1994) do show effects on automatic estimates with our procedure (Horton et al., 2001; Horton et al., 2005). Of particular interest was the finding that the subjects given an implicit stem completion task showed priming equivalent to that of the subjects in our speeded response group, suggesting that implicit stem completion may normally yield a relatively pure test of automatic retrieval. This finding is relevant to the present research, since it suggests that the stem completion task may not be subject to contamination from conscious retrieval and, thus, might provide a means of determining whether conscious access is required for release of retrieval inhibition (Basden \& Basden, 1998; E. L. Bjork et al., 1998). It also suggests that using three (Horton et al., 2005), two (Horton et al., 2001; Wilson \& Horton, 2002), or one practice test (as in Experiment 2 reported here) is inconsequential, because the implicit group received no practice tests and showed the same pattern as the speeded groups given varying numbers of practice tests.

The few published studies in which the implicit stem completion task has been used with a directed forgetting manipulation have yielded contradictory findings. All have used the item method of directed forgetting (but see David, Brown, Pojoga, \& David, 2000). Paller (1990) reported no reliable effect of directed forgetting in two studies, whereas Lehman, McKinley-Pace, Wilson, Slavsky, and Woodson (1997) and Hauselt (1998) reported small but reliable effects in each of three studies. Although there are several differences across the studies reported by Paller and those reported by Lehman et al. and Hauselt, a follow-up experiment reported by Paller (p. 1029) used a standard directed-forgetting procedure and again yielded no directed forgetting on stem completion but did yield a small directed-forgetting effect on fragment completion, thereby replicating the finding reported by MacLeod (1989; but see Suzuki, 2001).

\section{EXPERIMENT 1 Item Method}

In the first experiment, we used the item method of directed forgetting to compare directed-forgetting effects in an implicit group, a speeded response group, and a PDP group. We anticipated that the first two groups would yield equivalent effects of directed forgetting (Horton et al., 2001; Horton et al., 2005), although from the data cited earlier, it was not obvious that we should expect a directed-forgetting effect at all. On the basis of our previous work, we also expected that the PDP group would yield an underestimate of the automatic component in the directed-forgetting effect (Horton et al., 2005; Wilson \& Horton, 2002). Our immediate memory test allows for conscious estimates that are well above zero, and this is the condition that yields underestimates of automatic retrieval from the PDP model if automatic and conscious retrieval are correlated processes (Wilson \& Horton, 2002).

A second issue was of interest to us. The goal of PDP has been to isolate the contribution of conscious and automatic components to performance. As was noted above, a seminal assumption of PDP is that conscious and automatic retrieval exhibit an independence, rather than a redundancy, relation. There are empirical signatures that implicate a generate/recognize strategy, including differential baselines under inclusion and exclusion instructions and estimates of the automatic component that fall below baseline (Bodner et al., 2000; Jacoby, 1998; Toth et al., 1994; but see Richardson-Klavehn \& Gardiner, 1998). However, use of a generate/recognize retrieval strategy, which specifies a redundancy relation, does not always yield these signatures (Bodner et al., 2000). We extended our investigation to assess whether the PDP group engaged in a generate/recognize strategy.

Following the critical stem completion test, the subjects in the speeded response group were shown their responses to each of the stems and were asked to perform a modified inclusion or exclusion task on each response (David et al., 2000; Jacoby, 1998; Richardson-Klavehn \& Gardiner, 1996). In the inclusion task, the subjects let their speeded response stand if it was to the studied item or if they could not think of a studied item that completed the stem. If their speeded response was not to a studied item and they could think of a studied item, they provided that word. In the exclusion task, the subjects provided a word that was not previously studied. If their speeded response was not to a studied word, they let that stand as their response. When their speeded response was to a studied word, they provided a different word. If the inclusion and exclusion data of the speeded response group showed the signatures of generate/recognize but the data of the PDP group did not, we would conclude that the PDP group did not adopt a generate/recognize strategy, leaving open the possibility that they were conforming to the direct retrieval strategy required by PDP. However, if the data of the speeded response group (who clearly were engaging in generate/ recognize) mirrored those of the PDP group, this would 
suggest that the subjects in the PDP group might also be adopting generate/recognize strategies and, thus, would raise the possibility that the inclusion and exclusion tasks did not reliably operationalize the retrieval assumptions required for use of PDP.

\section{Method}

Subjects. A total of 48 introductory psychology students participated for course credit. Sixteen subjects were randomly assigned to each of three groups and were tested individually.

Design. The design was a $2 \times 2 \times 3$ incomplete mixed factorial. The within-subjects factors were type of cue (R or F) and test instruction (inclusion or exclusion). The between-subjects factor was group (implicit, speeded response, or PDP). The implicit group was not exposed to the inclusion/exclusion manipulation.

Materials. A total of 144 words were selected on the basis of a normative frequency of responding to three-letter stems of .15-.25 (Wilson, 1997). All the stems were unique and had more than one possible completion. No proper nouns were used.

Of the 144 words, there were 96 critical items, 12 buffer items, and 36 practice stems. Of the 96 critical items, 48 were randomly assigned to each of two study lists that were used equally often in each group. Three primacy and 3 recency buffer items were also assigned to each study list. The remaining 6 buffer items were used in the practice stem completion tests.

In the study trial, 24 words were paired with $\mathrm{R}$ cues and 24 with F cues. Over the course of the experiment, each word was followed equally often by $\mathrm{R}$ and $\mathrm{F}$ cues. The words were presented in a blockrandomized order, with 4 words paired with each of the two cues in each block of 8 study words.

On the practice stem completion tests, 12 and 24 stems, respectively, were presented on each of two tests. On each of four critical stem completion tests, the subjects saw stems for 12 studied ( $6 \mathrm{R}$ and 6 F) and 6 nonstudied words. The subjects in the PDP condition were given inclusion instructions on either the first and third or the second and fourth of these tests. Exclusion instructions were given on the other two tests. The subjects in the speeded response group received the same four critical tests, followed by the inclusion and exclusion tasks. Again, items in either the first and third or second and fourth of these tests were paired with inclusion instructions, and the other two were paired with exclusion instructions. Blocking of inclusion and exclusion tests was designed to minimize the subjects' confusion due to changing the task item by item (Bodner et al., 2000; Buchner, Erdfelder, \& Vaterrodt-Plünnecke, 1995; Graf \& Komatsu, 1994; Horton \& Vaughan, 1999).

Procedure. The subjects were instructed that the experiment was designed to examine the processing of familiar words. During the study phase, words were presented on a computer screen for $1 \mathrm{sec}$, followed immediately by a string of either three R or three $\mathrm{F}$ items. The $\mathrm{R}$ and $\mathrm{F}$ cues appeared for $2 \mathrm{sec}$ three lines below the words. The instructions emphasized that words followed by a string of $\mathrm{R}$ items were to be remembered for a subsequent unspecified memory test, whereas words followed by a string of $\mathrm{F}$ items should be forgotten.

Implicit and PDP groups. Following the study phase, the subjects in the implicit and PDP groups completed a filler task that lasted $4 \mathrm{~min}$, approximately the same time as that required to complete the practice stem completion tests by the speeded response group. The subjects in the implicit group then received the four critical stem completion tests, with instructions to say the first word that came to mind that would complete the stem. No reference was made to the relation between these stems and the study phase. The experimenter typed the responses into the computer while the subject observed.

The subjects in the PDP group were given the critical stem completion tests under inclusion and exclusion instructions. For inclusion, the subjects were instructed to use the three-letter stem to recall a word from the study phase. However, if they could not recall a studied word, they were to use the first word that came to mind. For exclusion, the subjects were instructed to use the three-letter stem to recall a word from the study phase, but then to respond with a different word. If they could not recall a studied word, they responded with the first word that came to mind. Before beginning the first inclusion and the first exclusion test, the subjects were shown four practice stems (two of which could be completed with buffer items from the study list).

Speeded response group. Immediately following the study phase, the subjects in the speeded response group were given two practice stem completion tests. Each stem appeared in the middle of the screen, preceded by a "+" sign for $500 \mathrm{msec}$. The instructions emphasized speed of responding. The subjects were fitted with a headset with a microphone connected to the computer to time the interval from onset of the stem to initiation of a vocal response. To focus these subjects on speed, they were told that they would be shown their average RTs at the end of each practice test and were encouraged to improve on these times as they went through the task (Horton et al., 2001).

Following the practice tests, the subjects in the speeded response group were presented the four critical stem completion tests and again were encouraged to continue responding as quickly as possible. Again, average RTs for these tests appeared at the end of each test so that the subjects could monitor their speed. No reference was made to the relation between these stems and the studied items. Following this generation phase, the subjects in this group were informed that they would next be shown their responses from the preceding stem completion tests. The modified inclusion instructions indicated that some of the three-letter stems to which they had just responded could be completed with previously studied words and others could not. Their task was to consider each of their responses from the critical tests as they were presented. If their response was a studied word, they simply left it and moved on to the next item. If their response was not a studied word and they could think of a studied word beginning with the three-letter stem, they provided the studied word. Finally, if they could not think of a studied word beginning with the three-letter stem, they responded with "not applicable."'2 They were told that it was important to use studied words on this task, regardless of whether those words had been followed by a string of $\mathrm{R}$ or $\mathrm{F}$ items during the study trial.

Under modified exclusion instructions, the subjects were given the same instructions, except that the focus was on using words that were not studied words. Thus, if the word given on the critical test was a studied word, the subjects provided a different word. If the word given previously was not a studied word, they left that word and moved on to the next item. Again, it was emphasized that it did not matter whether the word had been followed by a string of $\mathrm{R}$ or F items during the study trial. To ensure that the subjects understood the instructions, the first block of items with modified inclusion instructions and the first block of items with modified exclusion instructions began with four practice items, two of which were buffers on the study trial.

\section{Results}

An alpha of .05 was adopted for all statistical tests.

Response times. RT data were collected for the speeded response group on the practice and critical stem completion tests. The data appear in Table 1. For the analysis, RTs for the two practice tests were combined, as were the data from the four critical tests. Median RTs on the practice tests and on the baseline items of the critical tests did not differ $\left[F(1,15)=1.29, M S_{\mathrm{e}}=5,250\right]$, indicating that the subjects did not switch to a conscious retrieval strategy on the critical test when it was possible to use studied words to complete some stems (Horton et al., 2001; Wilson \& Horton, 2002). 
Table 1

Experiment 1: Median Response Times (in Milliseconds; With Standard Errors) for the Speeded Response Group on the Two Practice Stem Completion Tests and the Critical Stem Completion Test As a Function of Study Condition

\begin{tabular}{|c|c|c|c|c|c|c|c|c|c|c|}
\hline & & & & & \multicolumn{6}{|c|}{ Critical Test } \\
\hline & \multicolumn{2}{|c|}{$\begin{array}{c}\text { Practice } \\
\text { Test } 1\end{array}$} & \multicolumn{2}{|c|}{$\begin{array}{c}\text { Practice } \\
\text { Test } 2\end{array}$} & \multicolumn{2}{|c|}{ R Items } & \multicolumn{2}{|c|}{ F Items } & \multicolumn{2}{|c|}{$\begin{array}{c}\text { Baseline } \\
\text { Items }\end{array}$} \\
\hline & $M$ & $S E$ & $M$ & $S E$ & $M$ & $S E$ & $M$ & $S E$ & $M$ & $S E$ \\
\hline All items & 861 & 36 & 835 & 46 & 806 & 32 & 835 & 39 & 850 & 36 \\
\hline Targets only & - & & - & & 790 & 54 & 754 & 28 & 836 & 51 \\
\hline
\end{tabular}

Because RTs may be sensitive to directed-forgetting effects (Fleck, Berch, Shear, \& Strakowski, 2001; MacLeod, 1989; Whetstone, Cross, \& Whetstone, 1996), we also compared RTs for R, F, and baseline items in the speeded response group on the critical tests. The data appear in Table 1. Individual contrasts revealed no difference in the time to generate responses to stems of $\mathrm{R}$ items versus $\mathrm{F}$ items $\left[F(1,15)=1.29, M S_{\mathrm{e}}=5,536\right]$ or to the stems of $\mathrm{F}$ items versus baseline items $(F<1)$, but responses to $\mathrm{R}$ items were reliably faster than were responses to baseline items $\left[F(1,15)=5.53, M S_{\mathrm{e}}=5,695\right]$. Including only RTs for stems to which subjects generated the studied or designated baseline item, individual contrasts revealed no differences between $\mathrm{R}$ and $\mathrm{F}$ items $(F<1)$, $\mathrm{R}$ and baseline items $\left[F(1,15)=1.35, M S_{\mathrm{e}}=25,088\right]$, or $\mathrm{F}$ and baseline items $\left[F(1,15)=2.72, M S_{\mathrm{e}}=38,732\right]$. Variability was high due to the small number of items. The latter data are based on a minimum of four R items, four $\mathrm{F}$ items, and two baseline items for each subject. There was some suggestion of priming for the $\mathrm{R}$ and $\mathrm{F}$ items; however, these differences were not reliable when only RTs to target items were included. Caution is required in interpreting the results of these analyses, because of the small number of items.

Target completion rates. The RT data indicate that responses of the speeded response group on the critical tests were not contaminated with conscious retrieval. Next, we compared target completion rates of the speeded response and implicit groups to determine whether responses of the implicit group were contaminated with conscious retrieval. The data appear in Table 2. Consistent with previous data (Horton et al., 2001), there was no difference

Table 2

Experiment 1: Target Completion Rates and Priming Scores for the Implicit and Speeded Response Groups on the Critical Stem Completion Test

\begin{tabular}{|c|c|c|c|c|c|}
\hline \multirow[b]{2}{*}{ Group } & \multirow[b]{2}{*}{ Type of Cue } & \multicolumn{2}{|c|}{$\begin{array}{c}\text { Target } \\
\text { Completion } \\
\text { Rate }\end{array}$} & \multicolumn{2}{|c|}{ Priming } \\
\hline & & $M$ & $S E$ & $M$ & $S E$ \\
\hline \multirow[t]{2}{*}{ Implicit } & Remember & .47 & .03 & .26 & .03 \\
\hline & Forget & .40 & .03 & .20 & .03 \\
\hline \multirow[t]{2}{*}{ Speeded response } & Remember & .41 & .04 & .21 & .04 \\
\hline & Forget & .38 & .03 & .19 & .03 \\
\hline
\end{tabular}

between the two groups, nor was there an interaction with type of cue (both $F \mathrm{~s}<1$ ). There was reliably greater target completion for $\mathrm{R}$ items than for $\mathrm{F}$ items on the critical test $\left[F(1,30)=4.25, M S_{\mathrm{e}}=0.01\right]$. There was no difference in baseline rates for the two groups (speeded response, -.21 ; implicit, $-.20 ; F<1$ ). Given that the subjects in the speeded response group used automatic retrieval on the critical test, the target completion data show a directed-forgetting effect with automatic retrieval, and this effect is statistically equivalent for the speeded response and the implicit groups.

PDP estimates. The inclusion and exclusion data for the PDP group were used to calculate estimates of the automatic and conscious components of performance. The speeded response group provides an estimate of automatic retrieval from the target completion rates, but we can apply the PDP equations to derive estimates of automatic and conscious retrieval from the inclusion and exclusion responses of these subjects (recognizing that clearly, they did not engage in direct retrieval, as required by the independence assumption). ${ }^{3}$ Our interest in performing these calculations is to compare the estimates with those derived from the PDP group: If the two groups adopted the same strategy, despite the differences in procedure, we would expect parallel effects of directed forgetting on the conscious and automatic estimates. This would suggest that the subjects in the PDP group engaged in a generate/ recognize strategy, rather than in direct retrieval (Bodner et al., 2000; Jacoby, 1998).

Exclusion scores of 0 are sometimes considered a problem for calculating estimates of the automatic component of performance (Jacoby, 1998); therefore, we replaced exclusion scores of 0 with a score of half an item $(.5 / 12=$ .04 ; Horton \& Vaughan, 1999) in order to avoid the dilemma of removing the data of subjects who performed the exclusion task perfectly (Curran \& Hintzman, 1995). Deleting all the subjects with exclusion scores of 0 did not change the pattern of results. The data with and without exclusion scores of 0 appear in Table 3.

There was no difference in the proportion of baseline items completed by the PDP and speeded response groups on the inclusion and exclusion tests, nor was there an effect of test instruction (inclusion or exclusion) or an interaction (all $F_{\mathrm{s}}<1$ ). Lower baseline rates in the exclusion condition are a signature of a generate/recognize strategy (Bodner et al., 2000; Jacoby, 1998), but this signature was not evi- 
Table 3

Experiment 1: Inclusion and Exclusion Scores, Plus Estimates of Conscious and Automatic Components (Based on the Inclusion/Exclusion Data) As a Function of Group and Encoding Condition

\begin{tabular}{|c|c|c|c|c|c|c|c|c|c|c|c|c|c|}
\hline \multirow[b]{3}{*}{ Group } & \multirow[b]{3}{*}{ Type of Cue } & & & & & \multicolumn{4}{|c|}{ Conscious } & \multicolumn{4}{|c|}{ Automatic } \\
\hline & & \multicolumn{2}{|c|}{ Inclusion } & \multicolumn{2}{|c|}{ Exclusion } & \multicolumn{2}{|c|}{ 1st Est. } & \multicolumn{2}{|c|}{ 2nd Est. } & \multicolumn{2}{|c|}{ 1st Est. } & \multicolumn{2}{|c|}{ 2nd Est. } \\
\hline & & $M$ & $S E$ & $M$ & $S E$ & $M$ & $S E$ & $M$ & $S E$ & $M$ & $S E$ & $M$ & $S E$ \\
\hline \multirow[t]{3}{*}{ PDP } & Remember & .47 & .03 & .19 & .03 & .28 & .03 & .28 & .03 & .27 & .04 & .31 & .04 \\
\hline & Forget & .40 & .04 & .24 & .03 & .15 & .06 & .10 & .06 & .28 & .02 & .29 & .02 \\
\hline & Baseline & .19 & .03 & .24 & .03 & - & & - & & - & & - & \\
\hline \multirow[t]{3}{*}{ Speeded response } & Remember & .50 & .05 & .15 & .02 & .31 & .05 & .37 & .07 & .25 & .03 & .29 & .03 \\
\hline & Forget & .42 & .05 & .26 & .03 & .16 & .07 & .12 & .08 & .30 & .03 & .34 & .03 \\
\hline & Baseline & .22 & .03 & .22 & .03 & - & & - & & - & & - & \\
\hline
\end{tabular}

Note-Automatic estimates are based on the independence assumption. The first conscious and automatic estimates are based on data from all subjects; the second estimates are without subjects with $E=0$ scores. PDP, process dissociation procedure.

dent in either group, despite the obvious generate/recognize procedure assigned to the speeded response group.

Analysis of conscious estimates from the inclusion/exclusion data of the PDP and speeded response groups revealed a higher estimate for $\mathrm{R}$ than for $\mathrm{F}$ items $[F(1,46)=$ $15.92, M S_{\mathrm{e}}=0.03$ ] but no difference between groups and no interaction (both $F \mathrm{~s}<1$ ). Analysis of the automatic estimates revealed no reliable effects (all $\left.F_{\mathrm{S}}<1.75\right)$, and all automatic estimates were above baseline (but see Bodner et al., 2000; Richardson-Klavehn \& Gardiner, 1998; Russo \& Andrade, 1995). The lack of a reliable directedforgetting effect on automatic estimates in the PDP group is consistent with data reported by Russo and Andrade and, contrary to our concerns expressed earlier, suggests that the pattern of data they obtained was not an artifact of their instructions. In addition, these findings replicate the invariance in automatic estimates commonly reported (see, e.g., Jacoby, 1991, 1998; Jacoby et al., 1993; Jacoby, Yonelinas, \& Jennings, 1997). Notably, however, the failure to obtain a directed-forgetting effect in the automatic estimates of the PDP group is contrary to the finding of a directed-forgetting effect in the target completion data of the speeded response group.

Comparison of automatic estimates. A comparison of automatic estimates based on the target completion data of the speeded response group and the derived estimates for the PDP group confirmed that the PDP estimates were reliably lower $\left[F(1,46)=15.78, M S_{\mathrm{e}}=0.02\right]$. There was no effect due to the type of cue and no interaction (both $p \mathrm{~s}>$ .10). Using only the data from the PDP subjects with exclusion, scores greater than 0 did not alter the findings.

\section{Discussion}

Critical to the goals of the experiment was that the speeded response group showed clear evidence of automatic retrieval uncontaminated by conscious retrieval. A switch to conscious retrieval on the critical stem completion test would result in longer RTs (Horton et al., 2001; Horton et al., 2005; Richardson-Klavehn \& Gardiner, 1996, 1998; Vaterrodt-Plünnecke et al., 2002; Wilson \& Horton, 2002); however, the present data showed no evidence of this increase. Taken in conjunction with the find- ing that the speeded response group showed RTs on the critical test that were equivalent to those of the baseline group (Horton et al., 2001; Horton et al., 2005; Wilson \& Horton, 2002), we conclude that the speeded response task induced automatic retrieval without contamination from conscious retrieval. Other researchers have suggested that the lack of increase in RTs from the practice tests to the baseline items of the critical tests cannot be interpreted as unequivocal evidence that conscious retrieval did not occur on the critical tests. We recognize this as a possibility, but the magnitude of this conscious retrieval must be intractably small, given that conscious retrieval takes longer (as evidenced by the explicit condition tested in other studies) and given that we have not found a single instance of a reliable increase in RTs on the critical test in numerous replications of the speeded response task. Statistically equivalent target completion rates for the speeded response and the implicit groups further suggest that performance in the implicit group was also based on automatic retrieval, uncontaminated by conscious retrieval.

The target completion data of the speeded response and implicit groups on the critical test showed reliable directedforgetting effects. This finding in the implicit group replicates the findings of MacLeod (1989) with fragment completion and lexical decision (but see Paller, 1990; Suzuki, 2001). It appears that the directed-forgetting effect is evident in automatic retrieval (Basden \& Basden, 1998; E. L. Bjork et al., 1998; Russo \& Andrade, 1995), at least with the item method.

The remaining conclusions relate to the estimates of automatic and conscious retrieval from the inclusion and exclusion tasks. Estimates of conscious retrieval from the PDP and speeded response groups were higher for R items than for $\mathrm{F}$ items and did not differ across groups. Estimates of automatic retrieval also did not differ for the PDP and speeded response groups when estimates for the latter group were based on the inclusion/exclusion data. This finding implies that the two groups adopted similar strategies on the inclusion and exclusion tasks, notwithstanding the difference in instructions (see also Jacoby, 1998) and the temporal separation of the generation and recognition phases for the speeded response group. Importantly, these 
data contradict the target completion data in showing no directed-forgetting effect in automatic retrieval for the speeded response group. The lower estimates of automatic retrieval from the recognition data of the speeded response group, relative to the target completion data, are consistent with the hypothesis that automatic and conscious components of performance (as measured by the inclusion/ exclusion tests) were correlated (Curran \& Hintzman, 1995; Wilson \& Horton, 2002); specifically,

$$
p(A \mid C)>p(A)>p(A \mid \bar{C}) .
$$

If the estimate of automatic retrieval from the target completion data of the speeded response group quantifies $p(A)$, the lower estimate based on the inclusion and exclusion data indicates that $p(A)>p(A \mid \bar{C})$. The latter value is used to estimate $p(A)$ in the PDP calculations. This pattern suggests that automatic and conscious retrieval are correlated processes, which is not surprising given that this group performed what is clearly a generate/recognize task. Importantly, however, the parallel findings for the PDP group suggest that this group may have also used a generate/recognize strategy, rather than direct retrieval.

On the basis of a PDP analysis, Russo and Andrade (1995) reported a consistent reversal of the directedforgetting effect on automatic influences, although this effect was reliable only in a meta-analysis across two experiments. Our PDP group data show the same pattern, although we observed the typical statistical invariance in the automatic estimates. As was noted earlier, the results of Russo and Andrade's study were difficult to interpret because the instructions may have induced a generate/ recognize strategy, rather than direct retrieval. This remains a possible explanation of their data, notwithstanding their finding that inclusion and exclusion baseline rates did not reveal the signature of generate/recognize (Bodner et al., 2000). Indeed, our data suggest that both the PDP and the speeded response groups used a generate/recognize strategy on the inclusion and exclusion tests and, thus, that the finding of invariance in the automatic estimates for the PDP group may have been due to an underestimation of the contribution of automatic retrieval.

\section{EXPERIMENT 2 List Method}

The results of Experiment 1 replicate those of MacLeod (1989; but see E. L. Bjork \& R. A. Bjork, 1996; Suzuki, 2001 ) in showing directed forgetting in an implicit memory task using the item method. They further demonstrate that this effect can occur in automatic retrieval as indexed by target completion rates on the speeded response task. However, there have been no published studies in which the list method of directed forgetting preceded an implicit stem completion test, and it is the list method that provides the arena for retrieval inhibition (Basden \& Basden, 1998; E. L. Bjork et al., 1998). Experiment 2 was designed to determine whether directed-forgetting effects would obtain with the list method on a stem completion task. In addition, if conscious retrieval is required for directed forgetting in this paradigm, we would anticipate no difference between $\mathrm{R}$ and $\mathrm{F}$ items in the target completion data of the speeded response and implicit groups when responses were based on automatic retrieval. A different outcome might again be expected for the PDP group if the data from this group underestimated automatic retrieval.

\section{Method}

Subjects. A total of 72 undergraduates participated for course credit, with 24 students assigned to each of three groups in the order of their appearance at the lab. Either 16 or 17 students in each group participated in return for credit in their introductory psychology course, and the rest were paid $\$ 10$ for their participation. The subjects were tested in groups of up to 4 at a time, with each subject participating individually in a small cubicle in the lab.

Design. The design was the same $2 \times 2 \times 3$ incomplete mixed factorial as that used in Experiment 1.

Materials. A total of 144 words were selected from unpublished norms collected in our lab. All the words had unique three-letter stems with an average baseline rate of .20 . The subjects were presented 48 words on the study list and the same 48 items, along with an additional 48 items, on the critical stem completion test. The subjects in the speeded response group completed a practice test with stems from the remaining 48 words. The words were randomly selected from the pool for each task.

Following the study list, the subjects in the speeded response group completed the practice test. In lieu of the practice test, the subjects in the implicit and PDP groups were presented a filler task that took approximately the same amount of time as the practice test.

Subsequently, two critical stem completion tests were presented to all the subjects. The first test included 48 stems, with 12 from each of the R and F study lists (for each, 6 stems came from each of the first and second halves of their respective lists), and 24 nonstudied items. The second test included the remaining 12 items from each of the $\mathrm{F}$ and $\mathrm{R}$ study lists, along with the remaining 24 nonstudied items. Two stem completion tests were used (in comparison with four in Experiment 1) in order to minimize the number of switches between inclusion and exclusion tasks for the PDP group.

A block randomized presentation order was used for the two critical tests. Each block of eight stems included two stems from each of the R and F study lists (one from each half of each list) and four stems from the nonstudied items.

Procedure. The subjects were instructed to study a list of words in preparation for a memory test. The subjects were not informed of the nature of the memory test at this point. After the first 24 words had been presented, the study list was stopped, and the subjects were told that what they had just seen was a practice list to get them used to the procedure. They were instructed that they would not be tested on these items and that they should forget them. Instead, they should concentrate on the next list of words, because these words would be tested.

The test procedure for each group was identical to that in Experiment 1 , with the following exceptions. First, all the subjects typed their own responses after verbalizing them. Verbal responses were tape recorded for validation of the typed responses. Second, two, rather than four, critical tests were presented, with a break between them. Half of the subjects in the speeded response and PDP groups received the inclusion test first, and half received the exclusion test first.

\section{Results}

Response times. RT data for the speeded response group on the practice and critical tests appear in Table 4. RTs for the two critical tests were combined for this analysis. Analysis of median RTs on the practice test, in compari- 
Table 4

Experiment 2: Median Response Times (in Milliseconds; With Standard Errors) for the Speeded Response Group on the Practice Stem Completion Test and the Critical Stem Completion Test As a Function of Study Condition

\begin{tabular}{|c|c|c|c|c|c|c|c|c|}
\hline & \multicolumn{2}{|c|}{ Practice Test } & \multicolumn{2}{|c|}{$\begin{array}{l}\text { Critical Test: } \\
\text { R Items }\end{array}$} & \multicolumn{2}{|c|}{$\begin{array}{c}\text { Critical Test: } \\
\text { F Items }\end{array}$} & \multicolumn{2}{|c|}{$\begin{array}{l}\text { Critical Test: } \\
\text { Baseline } \\
\text { Items }\end{array}$} \\
\hline & $M$ & $S E$ & $M$ & $S E$ & $M$ & $S E$ & $M$ & $S E$ \\
\hline All items & 1,210 & 512 & 1,019 & 353 & 1,019 & 372 & 1,154 & 451 \\
\hline Targets only & - & & 927 & 281 & 890 & 273 & 1,060 & 372 \\
\hline
\end{tabular}

son with RTs for baseline items on the critical tests, yielded no significant difference $\left[F(1,31)=1.17, M S_{\mathrm{e}}=44,466\right]$, replicating the results of Experiment 1 and our previous work and indicating that the subjects did not switch to a conscious retrieval strategy on the critical tests.

The RT data for R, F, and baseline items in the speeded response group on the critical tests appear in Table 4. Individual contrasts using RTs to all stems, regardless of whether the subjects produced the target item, revealed shorter RTs to both $\mathrm{R}$ and $\mathrm{F}$ items, relative to baseline items $\left[F(1,31)=14.96, M S_{\mathrm{e}}=19,335\right.$, and $F(1,31)=$ $17.90, M S_{\mathrm{e}}=16,218$, respectively], but no difference between $\mathrm{R}$ and $\mathrm{F}$ items $(F<1)$. Including only RTs for stems to which the subjects generated the studied or designated baseline items yielded the same pattern, with reliably shorter RTs for both $\mathrm{R}$ and $\mathrm{F}$ items relative to baseline items $\left[F(1,31)=9.52, M S_{\mathrm{e}}=29,786\right.$, and $F(1,31)=$ $16.79, M S_{\mathrm{e}}=27,601$, respectively] and no difference between $\mathrm{R}$ and $\mathrm{F}$ items $(F<1)$. All but 1 subject met the criteria of a minimum of four $\mathrm{R}$ items, four $\mathrm{F}$ items, and two baseline items for the latter analysis. The subject who failed to meet the criteria completed two F items with targets; however, since the subject's median RT for F items was within $18 \mathrm{msec}$ of the group median, the data were retained in the analysis. The data indicate reliable $\mathrm{RT}$ priming for $\mathrm{R}$ and $\mathrm{F}$ items, in contrast to the results from Experiment 1, in which RTs were generally shorter for $\mathrm{R}$ items relative to baseline, but not for $\mathrm{F}$ items. The greater processing of $\mathrm{F}$ items in the list method seems the most likely account of the different outcomes in the two experiments.

Target completion rates. The RT data in Experiment 2 again showed no evidence of contamination with conscious retrieval in the speeded response group. Target completion rates of $\mathrm{R}$ and $\mathrm{F}$ items for the speeded response and implicit groups also did not differ $(F<1)$, and there was no interaction with type of cue $[F(1,62)=1.89$, $\left.M S_{\mathrm{e}}=0.01\right]$, suggesting that the responses of the implicit group were also not contaminated with conscious retrieval. The data appear in Table 5. This analysis revealed no difference in target completion rates for $\mathrm{R}$ and $\mathrm{F}$ items on the critical tests $(F<1)$. Baseline rates did not differ between the two groups [speeded response, -.19 ; implicit, -.21 ; $\left.F(1,30)=1.98, M S_{\mathrm{e}}=0.004\right]$. Contrary to the results of Experiment 1 with the item method, the target completion data showed no evidence of a directed-forgetting effect for automatic retrieval in the speeded response and implicit groups.

PDP estimates. To identify the patterns of automatic and conscious estimates, we completed a PDP analysis on the automatic and conscious estimates of the PDP and speeded response groups. As in Experiment 1, we replaced exclusion scores of 0 with a score of half an item, although deleting all the subjects with exclusion scores of 0 did not change the pattern of data. The data appear in Table 6 .

There was no difference in baseline rates for the PDP and speeded response groups on the inclusion and exclusion tests, nor was there an interaction of group and test instruction (both $F_{\mathbf{s}}<1$ ). Baseline rates for the exclusion task were slightly lower than those for the inclusion task $\left[F(1,62)=4.35, M S_{\mathrm{e}}=0.001\right]$.

Analysis of the conscious estimates from the inclusion and exclusion data revealed no reliable difference between the PDP and speeded response groups $[F(1,62)=2.47$, $\left.M S_{\mathrm{e}}=0.09\right]$. The main effect of type of cue was not reliable $\left[F(1,62)=2.40, M S_{\mathrm{e}}=0.02\right]$, but the interaction approached significance $[F(1,62)=3.35, p<.08]$, reflecting, curiously, a somewhat higher conscious estimate for $\mathrm{F}$ versus $\mathrm{R}$ items in the PDP group (see also Basden et al., 1993, Experiment 2). Analysis of the automatic estimates revealed no difference between groups and no interaction (both $F_{\mathrm{S}}<1$ ). There was also no difference between $\mathrm{R}$ and $\mathrm{F}$ items $\left[F(1,62)=2.86, M S_{\mathrm{e}}=0.02\right]$. All automatic estimates were above baseline. Again, these data replicate the invariance in automatic estimates commonly reported in PDP studies.

Baseline rates showed a small but reliable difference in Experiment 2 (Allen \& Vokey, 1998; Buchner et al., 1995; Jacoby, 1998). Accordingly, we reanalyzed the esti-

Table 5

Experiment 2: Target Completion Rates and Priming Scores for the Implicit and Speeded Response Groups on the Critical Stem Completion Test Target Completion

\begin{tabular}{|c|c|c|c|c|c|}
\hline \multirow[b]{2}{*}{ Group } & \multirow[b]{2}{*}{ Type of Cue } & \multicolumn{2}{|c|}{$\begin{array}{c}\text { Target } \\
\text { Completion } \\
\text { Rate }\end{array}$} & \multicolumn{2}{|c|}{ Priming } \\
\hline & & $M$ & $S E$ & $M$ & $S E$ \\
\hline \multirow[t]{2}{*}{ Implicit } & Remember & .41 & .02 & .20 & .02 \\
\hline & Forget & .38 & .02 & .17 & .02 \\
\hline \multirow[t]{2}{*}{ Speeded response } & Remember & .38 & .02 & .19 & .02 \\
\hline & Forget & .41 & .02 & .22 & .02 \\
\hline
\end{tabular}


Table 6

Experiment 2: Inclusion and Exclusion Scores, Plus Estimates of Conscious and Automatic Components (Based on the Inclusion/Exclusion Data) As a Function of Group and Encoding Condition

\begin{tabular}{|c|c|c|c|c|c|c|c|c|c|c|c|c|c|}
\hline \multirow[b]{3}{*}{ Group } & \multirow[b]{3}{*}{ Type of Cue } & & & & & \multicolumn{4}{|c|}{ Conscious } & \multicolumn{4}{|c|}{ Automatic } \\
\hline & & \multicolumn{2}{|c|}{ Inclusion } & \multicolumn{2}{|c|}{ Exclusion } & \multicolumn{2}{|c|}{ 1st Est. } & \multicolumn{2}{|c|}{ 2nd Est. } & \multicolumn{2}{|c|}{ 1st Est. } & \multicolumn{2}{|c|}{ 2nd Est. } \\
\hline & & $M$ & $\overline{S E}$ & $M$ & $\overline{S E}$ & $M$ & $\overline{S E}$ & $M$ & $\overline{S E}$ & $M$ & $\overline{S E}$ & $M$ & $S E$ \\
\hline \multirow[t]{3}{*}{$\mathrm{PDP}$} & Remember & .41 & .02 & .20 & .03 & .20 & .04 & .12 & .04 & .23 & .03 & .29 & .03 \\
\hline & Forget & .48 & .03 & .20 & .03 & .28 & .04 & .21 & .05 & .25 & .02 & .31 & .03 \\
\hline & Baseline & .10 & .01 & .08 & .01 & - & & - & & - & & - & \\
\hline \multirow[t]{3}{*}{ Speeded response } & Remember & .38 & .03 & .21 & .03 & .16 & .04 & .15 & .05 & .23 & .02 & .26 & .02 \\
\hline & Forget & .41 & .03 & .25 & .03 & .16 & .04 & .15 & .04 & .28 & .02 & .29 & .02 \\
\hline & Baseline & .09 & .01 & .08 & .01 & - & & - & & - & & - & \\
\hline
\end{tabular}

Note-Automatic estimates are based on the independence assumption. The first conscious and automatic estimates are based on data from all subjects; the second estimates are without subjects with $E=0$ scores. PDP, process dissociation procedure.

mates, using the correction suggested by Allen and Vokey. The analysis supported the same statistical conclusions as above, with conscious estimates decreasing by approximately .05 for both groups and automatic estimates decreasing by approximately .12 for the PDP group but remaining unchanged for the speeded response group. The large underestimate of automatic retrieval observed in the PDP group data above was not an artifact of different baseline rates in the inclusion and exclusion conditions.

Comparison of automatic estimates. A comparison of automatic estimates based on the target completion data of the speeded response group and the derived estimates for the PDP group confirmed that the PDP estimates were reliably lower $\left[F(1,62)=30.26, M S_{\mathrm{e}}=0.02\right]$. There was no effect due to the type of cue and no interactions (both $p \mathrm{~s}>.15$ ). Using only the data from PDP subjects with exclusion scores greater than 0 did not alter the findings.

\section{Discussion}

The RT data indicate that the speeded response group did not switch to a conscious retrieval strategy on the critical tests. The target completion data of the speeded response group and the automatic estimates derived from the inclusion and exclusion data for both the PDP groups and the speeded response group all indicated no directed-forgetting effect with the list method. The target completion data differ from those in Experiment 1 with the item method, where a reliable directed-forgetting effect was observed. This difference across the two experiments is readily explained in terms of the amount of processing accorded the $\mathrm{R}$ and $\mathrm{F}$ items. With the item method, subjects may withhold extensive processing until the cue is presented. Additional processing is carried out when an $\mathrm{R}$ cue appears, but not when an F cue appears. If this additional processing contributes to the automatic component of performance, a directed-forgetting effect would be expected. By contrast, subjects complete extensive processing on all items with the list method, since they have no reason, during the presentation of $\mathrm{F}$ items, to do otherwise. Consequently, no directed-forgetting effect occurred. This explanation is consistent with the lack of directed-forgetting effects in all published studies in which an implicit mem- ory task was used following the list method (Basden \& Basden, 1996; Basden et al., 1993; E. L. Bjork \& R. A. Bjork, 1996; Suzuki, 2001).

To ensure that the lack of a directed-forgetting effect was not the result of a feature of our procedure, we replicated the experiment with a group of 15 subjects. Instead of the implicit task, a standard free recall test followed the filler task. The results confirmed a small but reliable directed-forgetting effect $[t(14)=2.76, S E M=0.68]$, with better recall of $\mathrm{R}$ items than of $\mathrm{F}$ items (.34 vs. .24).

The lower automatic estimates from the inclusion/ exclusion data of the PDP and speeded response groups, in comparison with the target completion data of the speeded response group, are again consistent with the conclusion that the subjects in the PDP group adopted a generate/ recognize strategy, rather than direct retrieval, when completing the inclusion and exclusion tasks (Wilson \& Horton, 2002). Nonetheless, both analyses indicate no directedforgetting effect in the automatic estimates, leaving open the possibility that conscious retrieval may be required for directed-forgetting effects to appear under the list method, when such effects occur (as in a free recall test).

\section{GENERAL DISCUSSION}

Our data address two issues. The first is the role of automatic retrieval in directed forgetting. The second is the comparison of three measures of automatic retrieval. We adopted the stem completion task because there is little information available on this task with the directed-forgetting paradigm (and none with the list method of directed forgetting) and because this task has proven very fruitful in our investigations of the speeded response procedure.

Conscious and automatic retrieval with directed forgetting. Consistent with previous research (Horton et al., 2001; Horton et al., 2005; Wilson \& Horton, 2002), the results from both experiments showed no increase in RTs in the speeded response group when the subjects completed the critical test that included stems from the study trial. When subjects adopt a conscious retrieval strategy, RTs increase relative to use of an automatic retrieval strategy, whereas they show no increase when subjects con- 
tinue with automatic retrieval (Horton et al., 2001; Horton et al., 2005; Richardson-Klavehn \& Gardiner, 1998; Richardson-Klavehn et al., 1996; Toth, 1996; Wilson \& Horton, 2002). Thus, the RT data indicate that the subjects in the speeded response group adopted an automatic retrieval strategy throughout the stem completion tests.

The target completion data for the speeded response and implicit groups provide the key data on the role of automatic retrieval in directed forgetting. With the item method, a directed-forgetting effect was evident for automatic retrieval in the speeded response and implicit groups, with a higher target completion rate for $\mathrm{R}$ than for $\mathrm{F}$ items. By contrast, with the list method, there was no directed-forgetting effect in the target completion data. Indeed, the list method has invariably failed to yield a directed-forgetting effect with implicit tasks (Basden \& Basden, 1998), including fragment completion (Basden et al., 1993; E. L. Bjork \& R. A. Bjork, 1996; Suzuki, 2001), generating associates (Basden et al., 1993), and general knowledge (Basden \& Basden, 1996). Thus, directed forgetting can occur in the absence of conscious retrieval, but the evidence for this occurs only with the item method.

The lack of directed forgetting with automatic retrieval when the list method is used may reflect the greater processing accorded $\mathrm{F}$ items with this procedure. Alternatively, it may indicate that retrieval inhibition does not operate at the activation level of to-be-forgotten information but, rather, requires conscious access to the stored information (E. L. Bjork et al., 1998). The different results with the two methods do suggest, however, that the processing of studied items that occurs prior to any intention to learn those items does not solely determine implicit memory performance (cf. Masson \& MacLeod, 1992; Moscovitch, Vriezen, \& Gottstein, 1993) or, more particularly, the contribution of automatic influences: When subjects engage in additional processing following an $\mathrm{R}$ cue with the item method, automatic effects for $\mathrm{R}$ items are enhanced, relative to those for $\mathrm{F}$ items.

As was noted earlier, the common explanations of directed forgetting with the item and list methods are differential rehearsal and inhibition, respectively. Inhibition and selective rehearsal accounts of list method directed forgetting may not be inconsistent if the effect of the $\mathrm{F}$ cue at the end of the first list is to induce subjects to establish a new encoding context for the $\mathrm{R}$ items (Sahakyan \& Delaney, 2003): Lower memory for F items is then attributable to the new encoding context for the $\mathrm{R}$ items' inhibiting or blocking rehearsal of - and later reinstatement of the encoding context for-the F items. Furthermore, the lack of a directed-forgetting effect for subjects with the lowest overall memory performance (MacLeod et al., 2003 ) is readily accommodated in the inhibition account if subjects who do not do well do so because of a relative lack of effort that also causes them to not put much effort into imposing inhibition on $\mathrm{F}$ items (or switching to a new encoding context).

To determine whether an inhibitory mechanism is required, in addition to an explanation based on a change of encoding context, will require, at minimum, a more fully specified inhibitory mechanism. Conway et al. (2000) have described a process that takes a step toward this goal. They proposed that encoding of the second list ( $\mathrm{R}$ items) invokes inhibitory processes that disable the accessibility of the first list (F items) when the two lists are in competition with each other (e.g., unrelated lists). By contrast, when the lists are not in competition, the items in the two lists become integrated (e.g., the two lists include categorically related items). Although they do not specify exactly how these processes occur, their data showing reduced inhibition of List 1 items when List 2 learning is impaired suggest that retrieval of List 1 items during List 2 learning may be important. It is notable that such a process may implicate a selective rehearsal mechanism in which subjects strive to exclude List 1 items from the rehearsal set while learning List 2 . This selective rehearsal explanation receives support from the finding that it is the List 2 primacy items that show a very large recall deficit when subjects are given two consecutive $\mathrm{R}$ lists, rather than the typical F-list-R-list pairing (Sheard \& MacLeod, 2005): List 2 primacy items would be expected to show little advantage of their position in the list if subjects continued trying to rehearse previously studied items.

Sahakyan and Delaney (2003) have offered the context hypothesis, a rehearsal-based account of list method directed-forgetting effects, as an alternative to an inhibition account. They showed that subjects who changed encoding strategy either between the $\mathrm{F}$ and the $\mathrm{R}$ lists or between two R lists (for subjects given remember instructions for both lists) showed classic directed-forgetting effects. Specifically, those subjects who encoded the first list by using maintenance rehearsal strategies and encoded the second list by using a deeper level of encoding showed directed forgetting. The subjects who did not encode the first and second lists differently did not show directed forgetting. We would need to identify the strategies that our subjects adopted to determine whether a directed-forgetting effect occurs in automatic retrieval of one or the other of these two subgroups and whether the lack of a directedforgetting effect might be a result of averaging over these two distinct subgroups. But the absence of directedforgetting effects under the list method in implicit memory studies, including Experiment 2 here, indicates that an explanatory mechanism may be required only for situations in which subjects adopt a conscious retrieval strategy.

Comparison of methods for assessing automatic influences. The data replicate findings reported by Wilson and Horton (2002) in showing that the raw target completion data from the speeded response procedure yield higher automatic estimates than do the inclusion and exclusion data from the PDP. In addition, our data indicate that a stem completion task given under standard implicit instructions is likely completed using purely automatic retrieval, uncontaminated by conscious retrieval. The most likely explanation for the lower automatic estimates in the PDP group is that the subjects did not use (at least exclusively) a direct retrieval strategy. Rather, the pattern of data is consistent with a redundancy model - namely, that $p(A)>p(A \mid \bar{C})$, where $p(A)$ is defined as the auto- 
matic estimate derived from the target completion data of the speeded response group and $p(A \mid \bar{C})$ is defined as the automatic estimate derived from the PDP calculations. With redundant processes, a lower estimate of automatic retrieval with the PDP procedure is inevitable whenever the contribution of conscious retrieval is meaningfully greater than zero (Wilson \& Horton, 2002).

Why do the data not show evidence of direct retrieval? One explanation may be that a generate/recognize strategy is, for whatever reason, easier, the instructions notwithstanding. Alternatively, it may be that a pure direct retrieval strategy is simply not possible, although this depends on the theoretical approach one takes to automatic and conscious retrieval. Automatic retrieval can be viewed as conscious retrieval that runs off very quickly (perhaps without all the emergent properties of conscious retrieval) or as conscious retrieval with some components dropped out (thereby yielding faster responding). An alternative approach suggests that automatic and conscious retrieval are qualitatively different "mechanisms" that share certain processing stages (Curran \& Hintzman, 1997; Wilson \& Horton, 2002). Horton et al. (2001) suggested yet another possibility - specifically, that what we label as conscious retrieval normally connotes a substrate of automatic processes. Each of these models mandates a redundancy model of conscious and automatic retrieval, which would not allow for the direct retrieval required by PDP.

An alternative explanation is that explicit tasks (such as inclusion and exclusion) induce quite different processing than do implicit tasks, including our speeded response task (Horton et al., 2005). In particular, they may demand quantitatively or qualitatively different automatic retrieval processes. At a minimum, these two types of tasks certainly differ in whether they instruct subjects to impose output constraints on their responses (Buchner \& Wippich, 2000; Meier \& Perrig, 2000; see also Snodgrass, 2002). Imposing output constraints would certainly seem to emphasize the role of conscious retrieval. This perspective also has implications for other work. For example, Vaterrodt-Plünnecke et al. (2002) described a multinomial approach for assessing the relation between conscious and automatic retrieval, including in their approach both voluntary and involuntary conscious retrieval. To evaluate their approach, they included an implicit memory group to provide a pure measure of automatic retrieval (an assumption that may be justified on the basis of our data). If, however, the influence of automatic processes is not equivalent on implicit and explicit tests, using an implicit group as a comparison point for explicit groups would constrain the heuristic value of their model. A direct comparison of procedures across a series of tasks will be necessary to evaluate this approach.

\section{SUMMARY}

The research was designed to evaluate the role of automatic retrieval in directed forgetting, using the stem completion task. For the item method, the results showed a directed-forgetting effect in the automatic estimates for the speeded group, with a parallel effect for the implicit group, suggesting that the implicit group also used automatic retrieval on the stem completion task. By contrast, automatic estimates derived from the inclusion/exclusion data of both the speeded and PDP groups revealed no directed-forgetting effect. Directed-forgetting effects were not observed on the implicit task with the list method, consistent with previous studies, although a typically small but reliable directed-forgetting effect was observed with the list method when the subjects completed a free recall test. The data indicate that directed forgetting is evidenced in automatic retrieval for the item method, suggesting that automatic retrieval is augmented by the additional processing conducted on $\mathrm{R}$ items after the cue has been presented. The failure to find directed-forgetting effects on implicit tasks with the list method suggests that the additional processing received by all the items in this procedure eliminates directed-forgetting effects on automatic retrieval. Finally, the comparison of techniques for assessing automatic retrieval indicates that the subjects adopted a generate/recognize strategy on the inclusion/exclusion tasks, whether with a standard PDP task or following the speeded response task.

\section{REFERENCES}

Allen, S. W., \& Vokey, J. R. (1998). Directed forgetting and rehearsal on direct and indirect memory tests. In J. M. Golding \& C. M. MacLeod (Eds.), Intentional forgetting: Interdisciplinary approaches (pp. 173-195). Mahwah, NJ: Erlbaum.

Basden, B. H., \& Basden, D. R. (1996). Directed forgetting: Further comparisons of the item and list methods. Memory, 4, 633-653.

BASDEN, B. H., \& BASDEN, D. R. (1998). Directed forgetting: A contrast of methods and interpretations. In J. M. Golding \& C. M. MacLeod (Eds.), Intentional forgetting: Interdisciplinary approaches (pp. 139172). Mahwah, NJ: Erlbaum.

Basden, B. H., Basden, D. R., \& Gargano, G. J. (1993). Directed forgetting in implicit and explicit memory tests: A comparison of methods. Journal of Experimental Psychology: Learning, Memory, \& Cognition, 19, 603-616.

Basden, B. H., Basden, D. R., \& Morales, E. (2003). The role of retrieval practice in directed forgetting. Journal of Experimental Psychology: Learning, Memory, \& Cognition, 29, 389-397.

BJoRK, E. L., \& BJORK, R. A. (1996). Continuing influences of to-beforgotten information. Consciousness \& Cognition, 5, 176-196.

BJork, E. L., BJork, R. A., \& Anderson, M. C. (1998). Varieties of goal-directed forgetting. In J. M. Golding \& C. M. MacLeod (Eds.), Intentional forgetting: Interdisciplinary approaches (pp. 103-137). Mahwah, NJ: Erlbaum.

BJORK, R. A. (1972). Theoretical implications of directed forgetting. In A. W. Melton \& E. Martin (Eds.), Coding processes in human memory (pp. 217-235). Washington, DC: Winston.

BJORK, R. A. (1989). Retrieval inhibition as an adaptive mechanism in human memory. In H. L. Roediger III \& F. I. M. Craik (Eds.), Varieties of memory and consciousness: Essays in honor of Endel Tulving (pp. 309-330). Hillsdale, NJ: Erlbaum.

Bodner, G. E., Masson, M. E. J., \& Caldwell, J. I. (2000). Evidence for a generate-recognize model of episodic influences on word-stem completion. Journal of Experimental Psychology: Learning, Memory, \& Cognition, 26, 267-293.

Buchner, A., Erdfelder, E., \& VAterrodt-Plünnecke, B. (1995). Toward unbiased measurement of conscious and unconscious memory processes within the process dissociation procedure. Journal of Experimental Psychology: General, 124, 137-160. 
BuCHNER, A., \& WIPPICH, W. (2000). On the reliability of implicit and explicit memory measures. Cognitive Psychology, 40, 227-259.

Conway, M. A., Harries, K., Noyes, J., Racsma'ny, M., \& FranKISH, C. R. (2000). The disruption and dissolution of directed forgetting: Inhibitory control of memory. Journal of Memory \& Language, 43, 409-430.

Curran, T., \& Hintzman, D. L. (1995). Violations of the independence assumption in process dissociation. Journal of Experimental Psychology: Learning, Memory, \& Cognition, 21, 531-547.

Curran, T., \& Hintzman, D. L. (1997). Consequences and causes of correlations in process dissociation. Journal of Experimental Psychology: Learning, Memory, \& Cognition, 23, 496-504.

David, D., Brown, R., Pojoga, C., \& David, A. (2000). The impact of posthypnotic amnesia and directed forgetting on implicit and explicit memory: New insights from a modified process dissociation procedure. International Journal of Clinical \& Experimental Hypnosis, 48, 267-289.

Earles, J. L., \& Kersten, A. W. (2002). Directed forgetting of actions by younger and older adults. Psychonomic Bulletin \& Review, 9, 383388.

Fleck, D. E., Berch, D. B., Shear, P. K., \& Strakowski, S. M. (2001). Directed forgetting in explicit and implicit memory: The role of encoding and retrieval mechanisms. Psychological Record, 51, 207-221.

Geiselman, R. E., \& Bagheri, B. (1985). Repetition effects in directed forgetting: Evidence for retrieval inhibition. Memory \& Cognition, 13, 57-62.

Golding, J. M., Long, D. L., \& MacLeod, C. M. (1994). You can't always forget what you want: Directed forgetting of related words. Journal of Memory \& Language, 33, 493-510.

Golding, J. M., \& MacLeOD, C. M. (1998). Intentional forgetting: Interdisciplinary approaches. Mahwah, NJ: Erlbaum.

Graf, P., \& Komatsu, S. (1994). Process dissociation procedure: Handle with caution! European Journal of Cognitive Psychology, 6, 113-129.

Hauselt, J. (1998). An illusion of retrieval inhibition: Directed forgetting and implicit memory. In J. M. Golding \& C. M. MacLeod (Eds.), Intentional forgetting: Interdisciplinary approaches (pp. 197-218). Mahwah, NJ: Erlbaum.

Horton, K. D., \& Petruk, R. (1980). Set differentiation and depth of processing in the directed forgetting paradigm. Journal of Experimental Psychology: Human Learning \& Memory, 6, 599-610.

Horton, K. D., \& Vaughan, D. C. (1999). Analyzing estimates of automatic and conscious retrieval in between- and within-subjects designs. Behavior Research Methods, Instruments, \& Computers, 31, 347-352.

Horton, K. D., Wilson, D. E., \& Evans, M. (2001). Measuring automatic retrieval. Journal of Experimental Psychology: Learning, Memory, \& Cognition, 27, 958-966.

Horton, K. D., Wilson, D. E., Vonk, J., Kirby, S. L., \& Nielsen, T. (2005). Depth of processing and attentional effects on automatic retrieval: A comparison of implicit memory and process dissociation with the speeded response procedure. Acta Psychologica, 119, 235263.

JACOBY, L. L. (1991). A process dissociation framework: Separating automatic from intentional uses of memory. Journal of Memory \& Language, 30, 513-541.

JACOBY, L. L. (1998). Invariance in automatic influences of memory: Toward a user's guide for the process-dissociation procedure. Journal of Experimental Psychology: Learning, Memory, \& Cognition, 24, 3-20.

Jacoby, L. L., Toth, J. P., \& Yonelinas, A. P. (1993). Separating conscious and unconscious influences of memory: Measuring recollection. Journal of Experimental Psychology: General, 122, 139-154.

Jacoby, L. L., Yonelinas, A. P., \& Jennings, J. (1997). The relation between conscious and unconscious (automatic) influences: A declaration of independence. In J. Cohen \& J. W. Schooler (Eds.), Scientific approaches to consciousness (pp. 13-47). Mahwah, NJ: Erlbaum.

Lehman, E. B., McKinley-Pace, M. J., Wilson, J. A., Slavsky, M. D., \& Woodson, M. E. (1997). Direct and indirect measures of intentional forgetting in children and adults: Evidence for retrieval inhibition and reinstatement. Journal of Experimental Child Psychology, 64, 295-316.
MACLEOD, C. M. (1989). Directed forgetting affects both direct and indirect tests of memory. Journal of Experimental Psychology: Learning, Memory, \& Cognition, 15, 13-21.

MacLeod, C. M. (1999). The item and list methods of directed forgetting: Test differences and the role of demand characteristics. Psychonomic Bulletin \& Review, 6, 123-129.

MacLeod, C. M., Dodd, M. D., Sheard, E. D., Wilson, D. E., \& BIBI, U. (2003). In opposition to inhibition. In B. H. Ross (Ed.), The psychology of learning and motivation (Vol. 43, pp. 163-214). San Diego: Academic Press.

Masson, M. E. J., \& MacLeod, C. M. (1992). Reenacting the route to interpretation: Enhanced perceptual identification without prior perception. Journal of Experimental Psychology: General, 121, 145-176.

Meier, B., \& Perrig, W. J. (2000). Low reliability of perceptual priming: Consequences for the interpretation of functional dissociations between explicit and implicit memory. Quarterly Journal of Experimental Psychology, 53A, 211- 233.

Moscovitch, M., Vriezen, E., \& Gottstein, J. (1993). Implicit tests of memory in patients with focal lesions or degenerative brain disorders. In H. Spinnler \& F. Boller (Eds.), Handbook of neuropsychology (Vol. 8, pp. 133-173). Amsterdam: Elsevier.

PALlER, K. A. (1990). Recall and stem-completion priming have different electrophysiological correlates and are modified differentially by directed forgetting. Journal of Experimental Psychology: Learning, Memory, \& Cognition, 16, 1021-1032.

ReINGOLD, E. M., \& Toth, J. P. (1996). Process dissociations versus task dissociations: A controversy in progress. In G. Underwood (Ed.), Implicit cognition (pp. 159-202). New York: Oxford University Press.

Richardson-KlaVehn, A., \& Gardiner, J. M. (1996). Cross-modality priming in stem completion reflects conscious memory, but not voluntary memory. Psychonomic Bulletin \& Review, 3, 238-244.

Richardson-Klavehn, A., \& Gardiner, J. M. (1998). Depth-ofprocessing effects on priming in stem completion: Tests of the voluntary contamination, conceptual processing, and lexical processing hypotheses. Journal of Experimental Psychology: Learning, Memory, \& Cognition, 24, 593-609.

Richardson-Klavehn, A., Gardiner, J. M., \& JaVA, R. I. (1996). Memory: Task dissociations, process dissociations and dissociations of consciousness. In G. Underwood (Ed.), Implicit cognition (pp. 85158). Oxford: Oxford University Press.

Russo, R., \& AndRade, J. (1995). The directed forgetting effect in word-fragment completion: An application of the process dissociation procedure. Quarterly Journal of Experimental Psychology, 48A, 405-423.

Sahakyan, L., \& Delaney, P. F. (2003). Can encoding differences explain the benefits of directed forgetting in the list method paradigm? Journal of Memory \& Language, 48, 195-206.

Sheard, E. D., \& MacLeod, C. M. (2005). List method directed forgetting: Return of the selective rehearsal account. In N. Ohta, C. M. MacLeod, \& B. Uttl (Eds.), Dynamic cognitive processes (pp. 219248). Tokyo: Springer.

Snodgrass, M. (2002). Disambiguating conscious and unconscious influences: Do exclusion paradigms demonstrate unconscious perception? American Journal of Psychology, 115, 545-579.

SuzuKI, I. (2001). Directed forgetting with global directed forgetting instructions in an implicit and explicit memory test. Perceptual \& Motor Skills, 92, 903-909.

Тотн, J. P. (1996). Conceptual automaticity in recognition memory: Levels-of-processing effects on familiarity. Canadian Journal of Experimental Psychology, 50, 123-128.

Tотн, J. P., ReIngOLd, E. M., \& JACOBY, L. L. (1994). Toward a redefinition of implicit memory: Process dissociations following elaborative processing and self-generation. Journal of Experimental Psychology: Learning, Memory, \& Cognition, 20, 290-303.

Vaterrodt-Plünnecke, B., Krüger, T., \& BredenKamp, J. (2002). Process-dissociation procedure: A testable model for considering assumptions about the stochastic relation between consciously controlled and automatic processes. Experimental Psychology, 49, 3-26.

WeTZEL, C. D. (1975). Effect of orienting tasks and cue timing on the free recall of remember- and forget-cued words. Journal of Experimental Psychology: Human Learning \& Memory, 1, 556-566. 
Whetstone, T., Cross, M. D., \& Whetstone, L. M. (1996). Inhibition, contextual segregation, and subject strategies in list method directed forgetting. Consciousness \& Cognition, 5, 395-417.

WiLSON, D. E. (1997). Stem completion norms. Unpublished manuscript. Wilson, D. E., \& HorTon, K. D. (2002). Comparing techniques for estimating automatic retrieval: Effects of retention interval. Psychonomic Bulletin \& Review, 9, 566-574.

Zacks, R. T., Radvansky, G. A., \& Hasher, L. (1996). Studies of directed forgetting in older adults. Journal of Experimental Psychology: Learning, Memory, \& Cognition, 22, 143-156.

\section{NOTES}

1. This account resembles the set differentiation mechanism discussed in early accounts of directed-forgetting effects (R. A. Bjork, 1972). However, E. L. Bjork et al. (1998) argued that the retrieval inhibition process is different from a set differentiation mechanism: "Segregating or differentiating in memory the to-be-remembered items from the earlier to-be-forgotten items ... has nothing to do with inhibition" (p. 113). No more specific description of what subjects actually do to impose retrieval inhibition on the $\mathrm{F}$ items is provided, beyond the statement that subsequent learning is required for the inhibition to develop.
2. This procedure differs from a typical inclusion task because subjects are to say "not applicable" if the stem does not correspond to a studied item, rather than saying the first item that comes to mind. The latter requirement is necessary to capture automatic retrieval in situations in which conscious retrieval is unsuccessful. Of course, because our speeded response group used automatic retrieval to generate the first response, it was not necessary to estimate conditional automatic retrieval in this inclusion test.

3. This analysis parallels that described by Jacoby (1998) using a generate/recognize group, except that the inclusion and exclusion tests were temporally separated from the generation phase in our study. We also tested a variation on our speeded response group in this study, in which the subjects completed the speeded response task and then immediately completed the inclusion or exclusion task on that item. Analysis of the data for this group and the PDP group yielded the same statistical results for the conscious and automatic estimates as those reported here, except that the $F$ ratios in the analysis of the automatic estimates were all less than unity.

(Manuscript received June 18, 2003;

revision accepted for publication March 16, 2005.) 